\title{
The Rate of Fast-Food Consumption among Teenagers in Derna City $\backslash$ Libya
}

\author{
Fareha Hamd Younis*, Salwa Muftah Eljamay, Amna Mansour Eldali \\ Department of public Health Faculty of Medical Technology, Derna City - Libya
}

Received: 14 November 2019/ Accepted: 11 August 2020

Doi: https://doi.org/10.54172/mjsc.v35i1.211

\begin{abstract}
The purpose of this study is to find out about the fast-food consumption of adolescents between the ages of 13-25 years old in Derna city and its effect on health. The samples included 100 adolescents from both sexes, a descriptive cross-sectional study of teenagers was conducted. The questionnaire was divided into two parts: the first part was related to socio-demographic information and part two to junk food patterns and influencing factors of junk food consumption. A value of $\mathrm{P}<0.05$ was interpreted as statistically significant. The findings revealed that more girls $(67.0 \%)$ consumed fast food than boys, and approximately half $(49.0 \%)$ of participants were consuming fast food as an alternative to the main meal, and more than half of participants $(63.0 \%)$ were consuming soft drinks every day. The results concludes that adolescents consumed a greater amount of junk food, which subsequently led to a majority of ill effects.
\end{abstract}

Keywords: Nutrition; Fast Food; Junk Foods; Adolescents; Consumption; Teenagers.

\section{INTRODUCTION}

The term junk food refers to fast foods that are easy to make and quick to consume, Michael Jacobson aptly coined the phrase junk food in 1972 as slang for foods of useless or low nutritional values called HFSS (High fat, sugar, or salt) (Bhaskar, 2012). Junk food advertising also plays a great role in its popularity. However, it should be avoided, due to a lack of energy and high cholesterol. It causes a lot of harmful effects on the body like obesity, diabetes, heart disease, and various types of skin cancers. Reducing the temptation for junk food and developing awareness for fitness can help in eliminating junk food from a healthy diet regimen.

Junk foods lack nutritional value and are often high in fat, salt, sugar, and/or calories. Common junk foods include salted snack foods, fried fast-food, and carbonated drinks. Junk food has become a major problem and many countries are taking action - banning junk food advertising in children's programmers, removing it from schools, and even imposing a fat tax (Driskell et al., 2005). Many junk foods also contain trans fats. Trans fats behave like saturated fats when they enter the body. They clog up the human arteries and cause plaque to build up, contributing to heart disease and stroke symptoms (Prentice \& Jebb, 2003). It became necessary to study and determine the adverse effects of junk food consumption and associated problems. The study aimed to research the consumption of fast-food in teenagers in Derna city $\backslash$ Libya.

\section{MATERIALS AND METHODS}

Sample: The purpose of this study is to find out about the fast-food consumption of adolescents between ages 13-25 in Derna. The samples included 100 adolescents from both sexes, a descriptive cross-sectional study of teenagers was conducted. 
The questionnaire was divided into two parts: the first part was related to socio-demographic information and part two to junk food patterns and influencing factors of junk food consumption.

Place of the Study: The random sampling technique was used to choose government schools and colleges. About 15 students were randomly selected.

Statistical Analysis: Data were first entered in an Excel file, and then results were expressed as a mean and standard deviation. Chi-square was calculated to analyze data using SPSS version 24. A value of $\mathrm{P}<0.05$ was interpreted as statistically significant.

\section{RESULTS}

Junk food consumption was reported by all students in this study. The socio-demographic characteristics of the study participants are shown in Table 1. Of the 100 teenagers who participated in the study, ages of teenagers ranged from 13 to 25 years with a mean age of $19.5 \pm 3.4$ years. Approximately over half $(67.0 \%)$ of participates who consumed fast food were female, and about (33.0\%) were male. According to the age group, $30 \%$ of participants were in the age group of 13-17 years, $34 \%$ were in the age group of $18-21$ years and $36 \%$ were in the age group of $22-25$ years.
Table (1): Distribution of participants on the basis of socio-demographic characteristics $(n=100)$

\begin{tabular}{|c|c|}
\hline Teenager characteristic & No $\%$ \\
\hline \multicolumn{2}{|l|}{ Gender } \\
\hline Male & $33(33 \%)$ \\
\hline Female & $67(67 \%)$ \\
\hline \multicolumn{2}{|l|}{ Age } \\
\hline $13-17$ & $30(30 \%)$ \\
\hline $18-21$ & $34(34 \%)$ \\
\hline $22-25$ & $36(36 \%)$ \\
\hline \multicolumn{2}{|l|}{ Education level } \\
\hline Primary education & $3(3 \%)$ \\
\hline Secondary education & $33(33 \%)$ \\
\hline Higher secondary level education & $64(64 \%)$ \\
\hline \multicolumn{2}{|l|}{ Family income } \\
\hline 250-300 LYD & $6(6 \%)$ \\
\hline 350-400 LYD & $10(10 \%)$ \\
\hline 450-500 LYD & $34(34 \%)$ \\
\hline More than 500 LYD & $50(50 \%)$ \\
\hline \multicolumn{2}{|l|}{ Consumed junk food as } \\
\hline Meal & $64(64 \%)$ \\
\hline Snack & $36(36 \%)$ \\
\hline \multicolumn{2}{|l|}{ Family member ate junk food } \\
\hline Yes & $80(80 \%)$ \\
\hline No & $20(20 \%)$ \\
\hline \multicolumn{2}{|l|}{ Junk food healthy or not } \\
\hline Yes & $64(64 \%)$ \\
\hline No & $36(36 \%)$ \\
\hline \multicolumn{2}{|l|}{$\begin{array}{l}\text { Ate junk food as alternative to a } \\
\text { main meal }\end{array}$} \\
\hline Yes & $39(39 \%)$ \\
\hline No & $12(12 \%)$ \\
\hline Sometimes & $49(49 \%)$ \\
\hline
\end{tabular}

The majority of participants $64 \%$ had higher secondary level education, $33 \%$ had secondary education, and $3 \%$ had primary education. Income showed the majority of participants (50\%) came from a family that had a monthly income of more than $500 \mathrm{LYD}$, and $(6.0 \%)$ belonged to a family who's income was 250 300 LYD per month. Around $36 \%$ of participants consumed junk food as snacks, and about half $49 \%$ consumed junk food as an alternative to the main meal. Regarding health risks associated with junk food consumption, most of the participants (64.0\%), believed junk food to be healthy food, and the remaining $(36.0 \%)$, believed it to be unhealthy.

When data were analyzed by gender we found the proportion of junk food consumption as a 
meal in females was higher than males, and when analyzed by different groups of age, we found the proportion of junk food consumption of males (58.8\%) was higher than that of females in the age group 18-21year-old and a lower proportion (5.9\%) of males were in the age group 22-25-year-old. While the higher proportion $(42.6 \%)$ of females were in the age group 22- 25 and lower $(25.5 \%)$ proportion were in age group 18-21-year-old however, the relationship between both age and gender of participates and junk food consumption as a meal was not statistically significant $(\chi 2=9.18, \mathrm{p}$-value $=$ $0.10)$ as shown in table 2 .

Table (2). Distribution of junk food consumption as a meal among participants

\begin{tabular}{ccccc}
\hline \hline & Female & Male & & \\
\hline Age & No $\%$ & No $\%$ & $\chi 2$ & P-value \\
$13-17$ & $(15)$ & $(6)$ & 9.18 & 0.10 \\
& $31.9 \%$ & $35.3 \%$ & & \\
$18-21$ & $(12)$ & $(10)$ & & \\
& $25.5 \%$ & $58.8 \%$ & & \\
$22-25$ & $(20)$ & $(01)$ & & \\
& $42.6 \%$ & $5.9 \%$ & & \\
\hline \hline
\end{tabular}

When data were analyzed by gender, we found the proportion of junk food consumption as snacks in females was higher than males, and When analyzed by different groups of age, the proportion of junk food consumption as snacks in males $(43.0 \%)$ was higher than that of males in both age group 13-17 and 22-25-year-old, and a lower proportion (12.5\%) in the age group 18-21-year-old.

While the higher proportion of consuming junk food as snacks in females was $(40.0 \%)$ in the age group 22- 25 and the lower proportion $(30.0 \%)$, was found in both the age group 1317 and 18-21-year-old. However, the relationship between both age and gender of participates, and junk food consumption as snacks, was not statistically significant $\left(\chi^{2}=\right.$ 1.7 , -value $=0.423$ ), as shown in table 3 .

Data presented in table 4 showed that the most common type of junk food consumed every day was; $63.0 \%$ consumed soft drinks, followed by $54 \%$ frequently consumed Chips, $6 \%$ consumed French fries, 4\% consumed Pizza hut, 3\% consumed fried chicken, $2 \%$ consumed hamburger, and $1 \%$ consumed Chocolate.

Concerning consumption frequency, within 1 or 2 times per week, $17.0 \%$ consumed soft drinks followed by $23 \%$ who consumed Chips, $10 \%$ consumed French fries, 21 consumed Pizza hut, 21\% consumed fried chicken, 14\% consumed hamburgers, and $17 \%$ consumed Chocolate.

Table :(4).Frequency of junk food consumption

\begin{tabular}{cccccc}
\hline \hline Type of & $\begin{array}{c}\text { Every } \\
\text { day or } \\
\text { junk food } \\
\text { every } \\
\text { day }\end{array}$ & $\begin{array}{c}3 \text { or } 4 \\
\text { times } \\
\text { per } \\
\text { week }\end{array}$ & $\begin{array}{c}1 \text { or } 2 \\
\text { times } \\
\text { per } \\
\text { week }\end{array}$ & Rarely & Never \\
\hline $\begin{array}{c}\text { Soft drinks } \\
\text { French fries }\end{array}$ & $63 \%$ & $7 \%$ & $17 \%$ & $10 \%$ & $3 \%$ \\
$\begin{array}{c}\text { fried } \\
\text { chicken }\end{array}$ & $3 \%$ & $6 \%$ & $10 \%$ & $43 \%$ & $38 \%$ \\
Pizza hut & $4 \%$ & $12 \%$ & $21 \%$ & $55 \%$ & $8 \%$ \\
Chips & $54 \%$ & $15 \%$ & $23 \%$ & $6 \%$ & $2 \%$ \\
Chocolate & $1 \%$ & $2 \%$ & $17 \%$ & $13 \%$ & $2 \%$ \\
Hamburger & $2 \%$ & $5 \%$ & $14 \%$ & $67 \%$ & $12 \%$ \\
\hline \hline
\end{tabular}

\section{DISCUSSION}

In this study done in Derna-Libya, Junk food consumption was reported by all participants. The findings revealed that the proportion of junk food consumption in females $(67.0 \%)$ was higher than males, which was similar to the result by (SD \& Neupane, 2000). which said $(53.5 \%)$ who consumed junk food were girls. That may be because girls are more likely to be influenced by marketing campaigns that involved giveaways or competitions than males. Also, in this study, we corroborated the observation that older teenagers tend to eat fast food more frequently than younger teenagers. This was similar to what was reported by (Fanning et al., 2002) 
which said the probability of purchasing fast food increases until about 30 years of age.

On the other hand, higher education was correlated with greater frequency of fast food intake, which was similar to the result by (Hidaka et al., 2018) which said that fast food consumption is associated with higher education in women, but not men, among older adults in urban areas (Hidaka et al., 2018) i.e (That may be due to the fact that higher education correlates with a higher level of job involvement, including more complex work tasks and more responsibility).

Moreover, an annual family income of more than 500 LYD was related to increased fast food consumption by participates compared to an annual family income of (200-300 LYD). This was similar to what was reported in a study by (Fanning et al., 2002), which stated that the probability of an increase in consuming fast food increased with family income (Fanning et al., 2002).

Also, the finding shows that around $36 \%$ of participants consumed junk food as snacks and around half, $49.0 \%$ consumed junk food as an alternative to main meals which was similar to the result obtained by (Larson et al., 2008) in the United States, which showed the percentage of teenagers who skipped breakfast at least one day during the school week (Larson et al., 2008).

However, the relationship between both age and gender of participates and junk food consumption as a meal or as snacks was not statistically significant. Furthermore, in a study done in Australia by Denney-Wilson, $(25.0 \%)$ of students usually chose soft drinks instead of water or milk in comparison to the same reported by this study, where more than half of the participants $(63.0 \%)$ consumed soft drinks every day (Denney-Wilson et al., 2009).

\section{CONCLUSION}

The main conclusions of the experimental work should be presented. Based on junk food label indications, junk food calorie and nutrient labels show that package contents are high in calories, salt, and fats. Excess consumption of junk foods would lead rise to a wide variety of health disorders.

\section{REFERENCES}

Bhaskar, R. (2012). Junk food: impact on health. Journal of Drug Delivery and Therapeutics, 2 (3 .)

Denney-Wilson, E., Crawford, D., Dobbins, T., Hardy, L., \& Okely, A. D. (2009). Influences on consumption of soft drinks and fast foods in adolescents. Asia Pacific journal of clinical nutrition, 18(3), 447-452.

Driskell, J. A., Kim, Y.-N., \& Goebel, K. J. (2005). Few differences found in the typical eating and physical activity habits of lower-level and upper-level university students. Journal of the American dietetic association, 105(5), 798-801.

Fanning, J., Marsh, T. L., \& Stiegert, K. W. (2002). Determinants of fast food consumption .

Hidaka, B. H., Hester, C. M., Bridges, K. M., Daley, C. M., \& Greiner, K. A. (2018). Fast food consumption is associated with higher education in women, but not men, among older adults in urban safety-net clinics: A cross-sectional survey. Preventive medicine reports, $12,148-151$.

Larson, N. I., Neumark-Sztainer, D. R., Story, M. T., Wall, M. M., Harnack, L. J \& ‘. Eisenberg, M. E. (2008). Fast food intake: longitudinal trends during the 
transition to young adulthood and correlates of intake. Journal of Adolescent Health, 43(1), 79-86.

Prentice, A. M., \& Jebb, S. A. (2003). Fast foods, energy density and obesity :a possible mechanistic link. Obesity reviews, 4(4), 187-194.

SD, S., \& Neupane, S. (2000). Junk Food Consumption Among Secondary Level Students, Chitwan. Journal of Nepal Paediatric Society, 37(2 .( 


\title{
معدل استهلاك الاغذية السريعة بين المراهقين في درنة اليبيا
}

\author{
فريحة حمد يونس * ، سلوى مفتاح الجامعي ، أمنة منصور الدالي

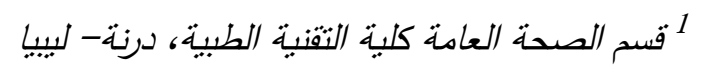

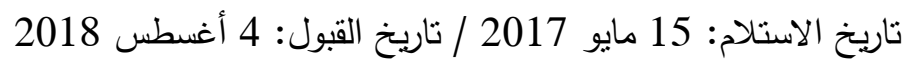
https://doi.org/10.54172/mjsc.v35i1.211:Doi

المستخلص : تهدف هذه الدراسة إلى التعرف على استهلاك الوجبات السريعة للمراهقين الذين تتراوح أعمارهم بين 13 و و25 سنة

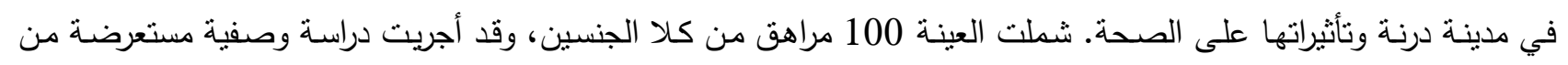

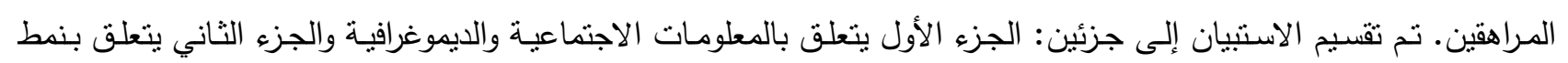

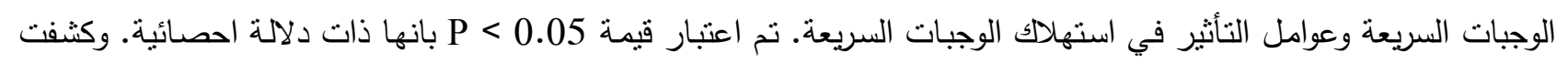

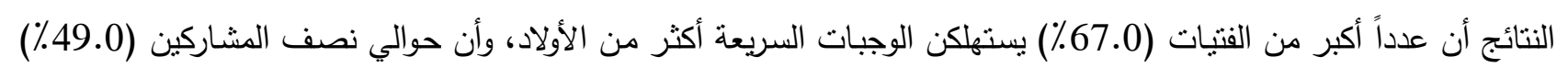

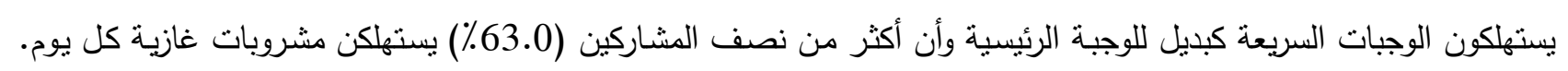

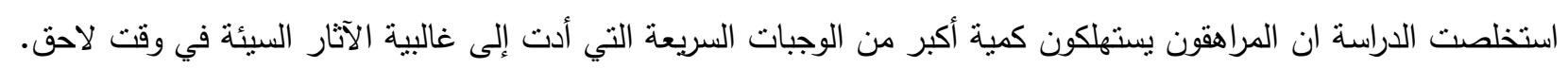
الكلمات المفتاحية : التغذية، الوجبات السريعة، المراهقين، الاستهلاك. 